\title{
Comparative Study of a Portable Prothrombin Time Monitor Employing Three Different Systems in Oral Anticoagulant Units
}

\author{
M. Vacas ${ }^{a}$ M.A. Fernández ${ }^{d} \quad$ F. Martínez-Brotons ${ }^{\text {e }}$ P.J. Lafuente ${ }^{b}$ \\ F. Ripolld C. Alvarez ${ }^{\mathrm{e}}$ J.A. Iriarte ${ }^{\mathrm{a}-\mathrm{c}}$ \\ aFIDEC Fundación para la Investigación y Docencia de las Enfermedades Cardiovasculares, \\ ${ }^{b}$ Departamento de Medicina Preventiva y Salud Pública, Facultad de Medicina y \\ Odontología, Universidad del País Vasco/Euskal Herriko Unibertsitatea, 'Hospital de Basurto, \\ Bilbao, dHospital Universitario La Fe, Valencia, and ${ }^{\mathrm{e}}$ Ciudad Sanitaria de Bellvitge, \\ Barcelona, Spain
}

\section{Key Words}

Prothrombin time - Portable monitor .

Anticoagulant treatment, oral

\begin{abstract}
The aim of this study was to evaluate the accuracy of the portable coagulometer CoaguChek $^{\circledR}$ (Roche Diagnostics) as a prothrombin time (PT) monitor, and to correlate capillary blood results with those of three different routine methods used for monitoring oral anticoagulant therapy (OAT): capillary, plasma and whole blood samples. Three hospitals participated in the study with a total of 235 patients on OAT. The international normalized ratio (INR) results obtained with Coa-
\end{abstract}

\begin{tabular}{ll}
\hline KARGER & ( ) 2001 S. Karger AG, Basel \\
0301-0147/01/0311-0018\$17.50/0 \\
$\begin{array}{l}\text { Fax +41 61306 1234 } \\
\begin{array}{l}\text { E-Mail karger@karger.ch } \\
\text { www.karger.com }\end{array}\end{array}$ & $\begin{array}{l}\text { Accessible online at: } \\
\text { www.karger.com/journals/hae }\end{array}$
\end{tabular}

guChek were compared with those obtained using each of the routine methods. The study presents a good correlation between the PT monitor and the three methods studied: $r=$ 0.9745 (hospital A), $r=0.9283$ (hospital B), $r=$ 0.9136 (hospital C). A simplified concordance test of the methods results in a nine-field comparison table showing concordances of $87.2,85.7$ and $68.4 \%$, respectively. The absolute difference (mean \pm SD) between laboratory $A$ and CoaguChek INRs was $0.0571 \pm$ 0.2042 , with values of $0.04286 \pm 0.3906$ for laboratory B and $0.6986 \pm 0.6170$ for laboratory $C$. These results confirm that CoaguChek could be used as a new method for oral anticoagulant monitoring, and is in best agreement with the capillary blood PT system.

Copyright $@ 2001$ S. Karger AG, Basel 


\section{Introduction}

Laboratory control of oral anticoagulant therapy (OAT) is based on prothrombin time (PT) [1]. Different combinations of thromboplastin reagents and techniques used in performing the PT test can introduce great variations in results despite the existence of the international normalized ratio (INR) [2]. The recent advent of portable coagulation monitors that measure PT from capillary whole blood samples has introduced new possibilities for oral anticoagulant monitoring [3-5]. The possibility of instantaneous results and the improvement in the quality of life of anticoagulated patients $[6,7]$ make it advisable to evaluate the accuracy and correlation of these devices with three routine laboratory systems used in oral anticoagulation units.

\section{Patients and Methods}

\section{Patients}

The study was performed in three hospitals: Ciudad Sanitaria de Bellvitge (Hospital A), Hospital de Basurto (Hospital B) and Hospital La Fe (Hospital C), with a similar number of patients undergoing OAT and stabilized over 6 weeks in an INR range between 2.0 and 4.0. The total number of patients was 235 , broken down as 77,84 and 74 patients, respectively. In the three hospitals, all patients gave their oral consent to participate in the study.

\section{Methods}

\section{PT Measurement}

Hospital A: Thrombotest in Capillary Blood Method. 77 patients on OAT with different therapeutic ranges of hypocoagulability underwent a simultaneous collection of capillary blood samples using a Microlance Long Point (Becton Dickinson, France) and rejecting the first drop. With an automatic pipette, $40 \mu \mathrm{l}$ of capillary blood were collected and put on the CoaguChek ${ }^{\circledR}$ PT test carrier to determine INR with CoaguChek. Another drop was put in a cuvette with bovine thromboplastin, ISI $=1.04$ (Thrombotest, Immuno), and INR was determined with the mechanical coagulometer Thrombotrak (Nicomed, Norway) as in the case of AMAX CS-190.

Hospital B: Plasma Sample. 84 patients on OAT with a therapeutic range between 2 and 4 were included in the study. The blood was extracted by venipuncture and placed in siliconized vacuum glass tubes (Becton Dickinson), previously filled to $1 / 10$ volume with $0.129 M$ trisodium citrate and centrifuged to $1,500 \mathrm{~g}$ for $15 \mathrm{~min}$ at $4{ }^{\circ} \mathrm{C}$. The clinical laboratory methodology for INR measurements employed an STA coagulometer (Diagnostics Stago, Barcelona, Spain), and the rabbit thromboplastin STA Neoplastine Plus (Diagnostica Stago) with an ISI = 1.29 supplied by the manufacturer. The mean normal PT was determined by the geometrical mean of 20 fresh normal plasmas.

Hospital C: Thrombotest in Venous Whole Blood. 74 patients on OAT with different intensities of hypocoagulability and different diagnoses participated in the study. The samples were obtained from venipuncture in siliconized and vacuum tubes containing 0.129 $M$ sodium citrate (Vacutainer, Sumilab) $(1 / 10)$ and tested immediately in the coagulometer AMAX CS190 (Grifols, Barcelona, Spain), ISI $=0.92$. AMAX is a mechanical coagulometer that measures the time from the addition of the starting reagent up to the beginning of fibrin formation. The sample of whole blood and the reagent are put into a special cuvette which is inserted into one of the mechanical measuring wells. A stainless steel ball is placed on the bottom of the cuvette. Upon addition of the starting reagent, the cuvette starts to rotate around its longitudinal axis, while the steel ball is kept exactly in place by a magnet. When coagulation starts, the fibrin filaments drag the ball away from the original site. This change in position releases an impulse in the magnetic sensor which automatically stops the time recording. All samples were analyzed in duplicate. To check the perfect reconstitution of the lyophilized material and the functioning of the coagulometer we used a control plasma (Control Plasma AK-R from Immuno).

Method of CoaguChek. The portable coagulometer to be evaluated was a CoaguChek (Roche Diagnostics, Barcelona, Spain). One drop of capillary whole blood was collected from the patient's finger using the lancet device Softclix (Boehringer-Mannheim, Germany) containing iron oxide particles and reagent which mix by an oscillating electromagnetic field when the whole blood sample is applied. At the start of coagulation, the iron particles stop their movement. This change is detected by reflectance photometry. A code chip for each lot of CoaguChek PT test provides all necessary calibration information: the ISI value and the mean 
Fig. 1. Comparison between CoaguChek and Thrombotest (TT) in capillary blood. Coefficient of correlation: $r=0.974$; regression analysis: $\mathrm{y}=0.0709+0.995 \mathrm{x} . \mathrm{R}^{2}=$ 0.9489 .

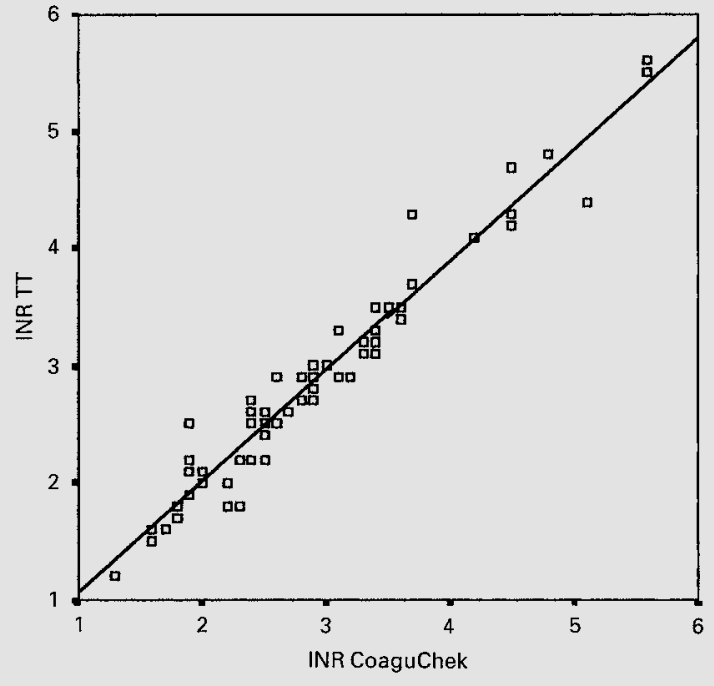

\section{Results}

The mean and standard deviation of the INR obtained with the four methods are given in table 1.

Figures 1-3 graphically represent the regression lines obtained comparing the CoaguChek monitor with the three systems studied. In all cases a good correlation is observed: $\mathrm{r}=$ 0.974 (Hospital A), $\mathrm{r}=0.928$ (Hospital B) and $r=0.914$ (Hospital C).

Regarding the test of simple concordance, tables 2-4 present the comparison of CoaguChek with each of the other systems, showing $87.2 \%$ agreement with the Thrombotest/KC1 system, $85.7 \%$ with the Neoplastine/STA system and $68.4 \%$ with Thrombotest/AMAX. If the kappa index is applied, these values are $0.719,0.656$ and 0.358 , respectively.

Figures 4-6 represent the plotting of the average INR value of a pair of measurements versus their difference. The absolute difference (mean $\pm \mathrm{SD}$ ) in laboratory A and Coaobtained in case both observers agree, ruling out chance $\left(100-\mathrm{P}_{\mathrm{e}}\right)$. 
Fig. 2. Comparison between the CoaguChek and the Neoplastine/ STA system. Coefficient of correlation: $\mathrm{r}=0.928$; regression analysis: $\mathrm{y}=0.485+0.839 \mathrm{x} . \mathrm{R}^{2}=0.8609$.

Fig. 3. Comparison between CoaguChek and Thrombotest in whole blood (AMAX). Coefficient of correlation: $r=0.914$; regression analysis: $\mathrm{y}=0.631+0.617 \mathrm{x} . \mathrm{R}^{2}=$ 0.8347 .

Table 1. INR mean and SD with CoaguChek and the three studied systems
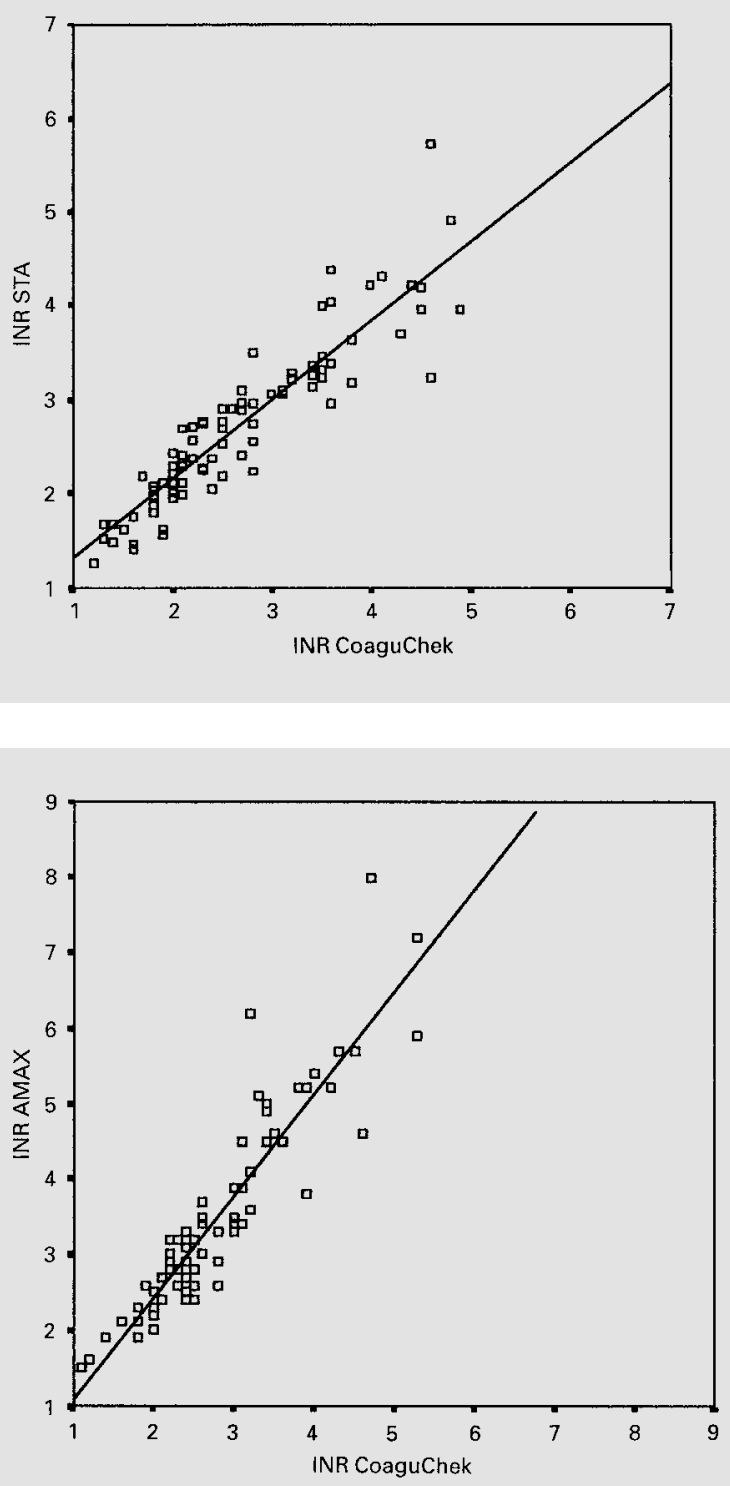

\begin{tabular}{lllll}
\hline Lab & Patients & Routine system & $\begin{array}{l}\text { INR } \\
\text { routine system }\end{array}$ & $\begin{array}{l}\text { INR } \\
\text { CoaguChek }\end{array}$ \\
\hline A & 77 & Thrombotest/KC-1 & $2.83 \pm 0.88$ & $2.89 \pm 0.90$ \\
$\mathrm{~B}$ & 84 & Neoplastine/STA & $2.78 \pm 0.95$ & $2.74 \pm 1.05$ \\
$\mathrm{C}$ & 74 & Thrombotest/AMAX & $3.47 \pm 1.31$ & $2.77 \pm 0.88$ \\
\hline
\end{tabular}


Table 2. Comparison between CoaguChek PT test and Thrombotest in capillary blood: frequency distribution of measured values $(n=77)$

\begin{tabular}{lccl}
\hline Thrombotest/ & \multicolumn{3}{l}{ CoaguChek PT system } \\
\cline { 2 - 4 } KC-1 system & INR $<2$ & INR 2-4 & INR $>4$ \\
\hline INR $<2$ & $10(13.0)$ & $5(6.5)$ & \\
INR 2-4 & $4(5.2)$ & $49(63.6)$ & $1(1.3)$ \\
INR $>4$ & & & $8(10.4)$
\end{tabular}

Figures in parentheses represent percentage. Concordance $=87 \%$; kappa index $=71.8 \%$

Table 3. Comparison between CoaguChek PT test and the Neoplastine/STA system. Frequency distribution of measured values $(n=84)$

\begin{tabular}{lccc}
\hline Neoplastine/ & \multicolumn{3}{l}{ CoaguChek PT system } \\
\cline { 2 - 4 } STA system & INR $<2$ & INR 2-4 & INR $>4$ \\
\hline INR $<2$ & $14(16.7)$ & $1(1.2)$ & \\
INR 2-4 & $4(4.8)$ & $52(61.9)$ & $4(4.8)$ \\
INR $>4$ & & $3(3.6)$ & $6(7.1)$ \\
\hline
\end{tabular}

Figures in parentheses represent percentage. Concordance $=85.7 \%$, kappa index $=65.6 \%$.

Table 4. Comparison between CoaguChek PT test and Thrombotest in whole blood: frequency distribution of measured values $(\mathrm{n}=74)$

\begin{tabular}{llrr}
\hline Thrombotest/ & \multicolumn{3}{l}{ CoaguChek PT system } \\
\cline { 2 - 4 } AMAX system & INR $<2$ & INR 2-4 & INR $>4$ \\
\hline INR $<2$ & $5(6.8)$ & $9(12.2)$ & \\
INR 2-4 & & $40(54.1)$ & $13(17.6)$ \\
INR $>4$ & & & $7(9.5)$
\end{tabular}

Figures in parentheses represent percentage. Concordance $=70.4 \%$; kappa index $=39.0 \%$.
guChek INRs was $0.0571 \pm 0.2042,0.04286$ \pm 0.3906 in laboratory $\mathrm{B}$ and $0.6986 \pm$ 0.6170 in laboratory C. The $95 \%$ limits of agreement of INR difference versus the average were $0.0106 \div 0.1037$ (laboratory A), $-0.1490 \div 0.1276$ (laboratory B) and $0.5557 \div$ 0.8416 (laboratory $\mathrm{C}$ ). The coefficients of correlation between the INR average value of a pair of measurements versus their difference in the studied systems were $0.0089,0.069$ and 0.4942 , respectively.

\section{Discussion}

Although Thrombotest in KC-1 has already been compared with CoaguChek [11, 12], we were interested in the results of testing Thrombotest with two different blood samples, capillary and whole venous blood. When we compared the INR results, the monitor showed a good correlation with capillary blood sample, yielding a figure $(0.974)$ which is similar to the values obtained in other studies $(0.910,0.997)$. With Thrombotest in whole venous blood we found a coefficient of correlation of 0.914 , which is the same as in the study of Kapiotis et al. [11] with capillary blood.

The laboratory that determined PT using the Neoplastine/STA system in citrated venous plasma obtained a similar correlation as that in other studies [13].

In the comparison of absolute differences (mean $\pm \mathrm{SD}$ ), Thrombotest in whole venous blood data presented the greatest variability $(0.6986$, IC: $0.5557 \div 0.8416)$ evidenced by a larger coefficient of correlation, $r=0.4942$, compared to the other two laboratories (0.0571, IC: $0.0106 \div 0.1037, r=0.0089$ for laboratory A and 0.04286 , IC: $-0.1490 \div$ $0.1276, r=0.0690$ for laboratory B). This variability was confirmed when the $95 \%$ limits of agreement of the INR difference versus 
Fig. 4. INR differences for patients by CoaguChek and Thrombotest (TT) in capillary blood. INR differences (DCOAG-TT) and mean INR (XCOAG-TT) are shown.

Fig. 5. INR differences for patients by CoaguChek and the Neoplastine/STA system. INR differences (DCOAG-STA) and mean INR (XCOAG-STA) are shown.
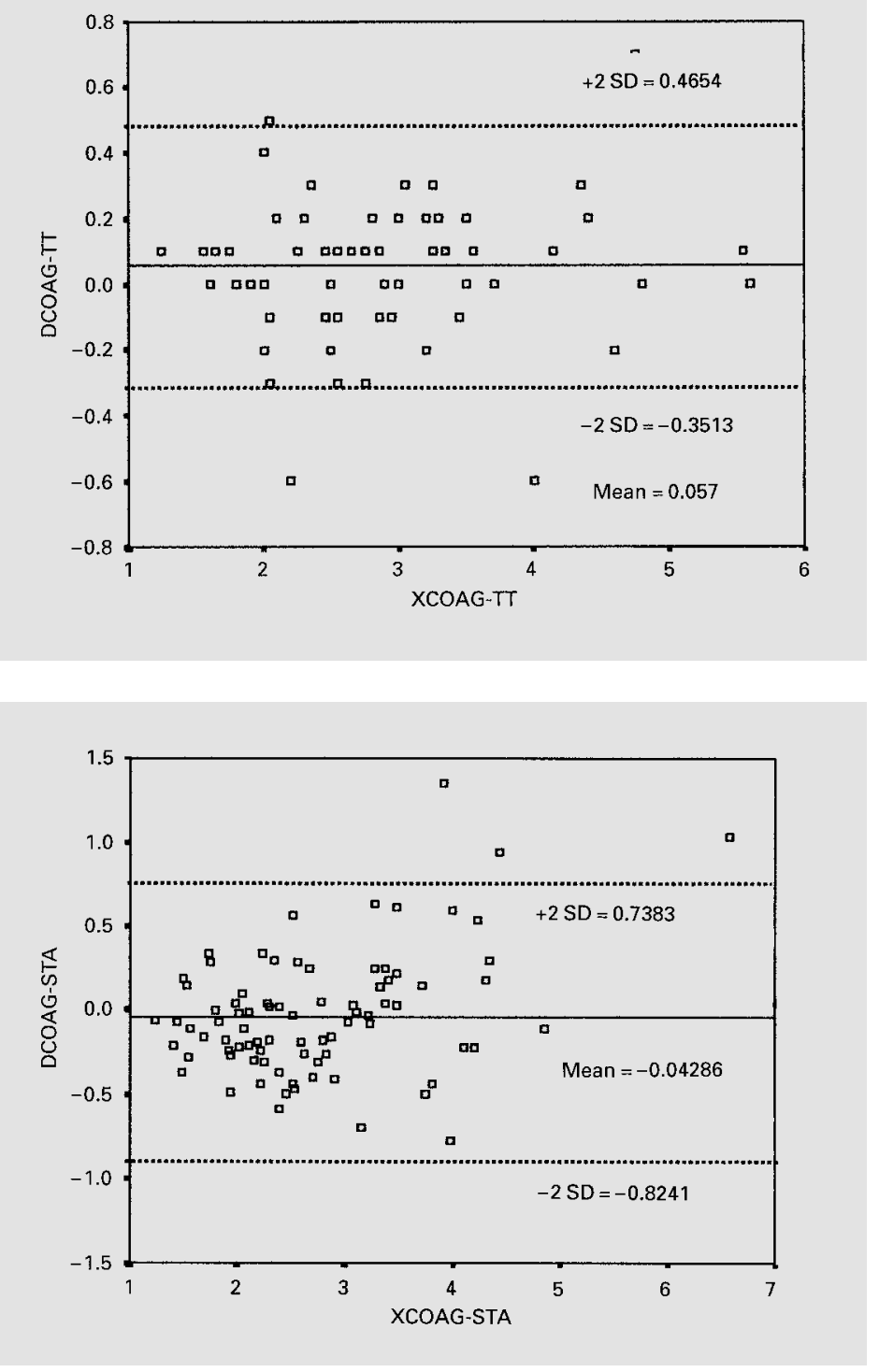

the average were calculated: -0.35134 to $0.4654,-0.8214$ to 0.7383 and -1.9326 to 0.5354 . The increase in the variability of the results corresponded to an increase in the magnitude of the measurements. The system of laboratory A with Thrombotest in KC-1

Oral Anticoagulant Treatment and Portable Monitor had a coefficient of correlation close to zero, showing a lower dispersion.

In the simple concordance studies, CoaguChek tended to exceed Thrombotest whole venous blood INR results, since $18.9 \%$ of the INR values were incremented (12.2\% in INR 
Fig. 6. INR differences for patients by CoaguChek and Thrombotest in whole blood. INR differences (DCOAG-AMAX) and mean (XCOAG-AMAX) are shown.

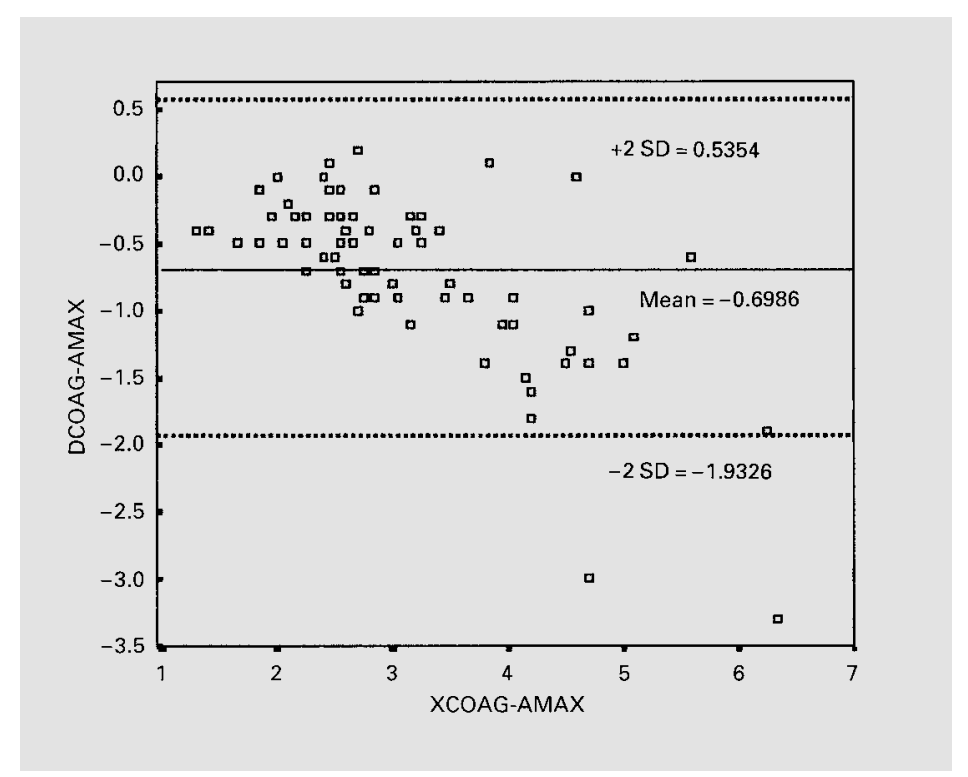

$<2$ and $16.6 \%$ in INR $=24$ ). The percentage of concordance with this method was lower $(70.4 \%$, kappa index $=0.39)$ than when using the other systems: $87 \%$ and kappa index = 0.718 for laboratory A and $85.7 \%$ and kappa index $=0.656$ for laboratory B.

This study showed that CoaguChek INR results are in better agreement with Thrombotest capillary blood results than in Thrombotest venous whole blood results. The use of high sensitivity thromboplastin in the two methods would seem to indicate that the dif- ference in the results may be caused by differences in preanalytical conditions [3].

On the basis of our experience with the use of this kind of monitor, we feel it is a viable alternative to laboratory testing and an optional method for monitoring anticoagulated patients. To this end, the sensitivity of the thromboplastins used in these devices must first be calibrated against international reference preparations, and a correlation study should be done with the routine method used as a reference.

\section{References}

1 Quick AJ: The prothrombin in haemophilia and in obstructive jaundice. J Biol Chem 1935;109:72.

2 van den Besselaar AMHP, Evatt BL, Brogan DR, Triplett DA: Proficiency testing and standardisation on prothrombin time: Effect of thromboplastin, instrumentation and plasma. Am J Clin Pathol 1984;82: 688699.
3 Ansell J, Holden A, Knapic N: Patient self-management of oral anticoagulation guided by capillary (fingerstick) whole blood prothrombin time. Arch Intern Med 1989;149: 2509-2511.

4 van den Besselaar AMHP, Breddin K, Lutze G, Parker-Williams J, Taborski U, Vogel G: Multicenter evaluation of a new capillary blood pro- thrombin time monitoring system. Blood Coagul Fibrinolysis 1995;6: 726-732.

5 Tripodi A, Arbini AA, Chantarangkul V, Bettega D, Mannuci PM: Are capillary whole blood coagulation monitors suitable for the control of oral anticoagulant treatment by the international normalized ratio? Thromb Haemost 1993;70:921-924. 
6 Anderson DR, Harrison L, Hirsh J: Evaluation of a portable prothrombin time monitor for home use by patients who require long-term oral anticoagulant therapy. Arch Intern Med 1993;153:1441-1447.

7 Bernardo A, Halhuber C, Horstkotte D: Home prothrombin estimation; in Thrombosis, Embolism and Bleeding. London, ICR, 1992, pp 325-330.

8 Bland JM, Altman DG: Comparing methods of measurement: Why plotting difference against method is misleading. Lancet 1995;346:10851087.
9 Sackett DL, Haynes RB, Tugwell P: Clinical Epidemiology: A Basic Science for Clinical Medicine. Boston, Little, Brown, 1985.

10 Fleiss JL: The Design and Analysis of Clinical Experiments. New York, Wiley, 1986.

11 Kapiotis S, Quehenberger P, Speiser $\mathrm{W}$ : Evaluation of the new method Caoguchek $^{\circledR}$ for the determination of prothrombin time from capillary blood: comparison with Thrombotest with KC-1. Thromb Res 1995; 77:563-567.
12 Ruzicka K, Kapiotis S, Quehenberger P, Handler S, Speiser W: Evaluation of bedside prothrombin time and activated partial thromboplastin time measurement by coagulation analyser CoaguChek Plus in various clinical settings. Thromb Res 1997;87:431-440.

13 Vacas M, Lafuente PJ, Cuesta S, Iriarte JA: Comparative study of portable monitor for prothrombin time determination, CoaguChek, with three systems for control of oral anticoagulant treatment. Haemostasis 1998;28:321-328. 